\title{
DIREITO INTERGERACIONAL E REFORMA DA PREVIDÊNCIA
}

\section{INTERGERATIONAL LAW AND PENSION REFORM}

\author{
Viviane Coêlho De Séllos-Knoerr ${ }^{1}$ \\ Priscila Luciene Santos De Lima ${ }^{2}$ \\ Maria Carolina Carvalho De Almendra Freitas ${ }^{3}$
}

\begin{abstract}
RESUMO
O presente artigo trata da necessidade de maior estruturação doutrinária, especialmente por parte dos juristas brasileiros, que ficam especialmente atrelados à questão da solidariedade intergeracional ambiental. Assim, é preciso expandir a temática para outras áreas que também demandam a aplicação desse direito, como o direito previdenciário. Através da pesquisa na doutrina portuguesa, constatou-se que o direito intergeracional é um direito fundamental das futuras gerações. Assim, o cumprimento do direito fundamental ao pacto intergeracional deve ser realizado em um debate tecnicista que equilibre os interesses das gerações futuras, sem sucumbir os planos progressivos da atual geração.
\end{abstract}

PALAVRAS-CHAVES: Intergeracional; Reforma; Previdência.

\begin{abstract}
This article deals with the need for greater doctrinal structuring, especially by brazilian jurists, who are especially tied to the issue of environmental intergenerational solidarity. Thus, it is necessary to expand the theme to other areas that also demand the application of this right, such as social security law. Through research in portuguese doctrine, it was found that intergenerational law is a fundamental right of future generations. Thus, the fulfillment of the fundamental right to the intergenerational pact must be carried out in a technical debate that balances the interests of future generations, without succumbing to the progressive plans of the current generation.
\end{abstract}

KEYWORDS: Intergenerational; remodeling; welfare.

\section{INTRODUÇÃO}

\footnotetext{
${ }^{1}$ Doutora em Direito do Estado pela Pontifícia Universidade Católica de São Paulo. Mestre em Direito das Relações Sociais pela Pontifícia Universidade Católica de São Paulo. Graduada em Direito pela Universidade Federal do Espírito Santo. É advogada. Professora e Coordenadora do Programa de Mestrado e Doutorado em Direito Empresarial e Cidadania do Centro Universitário Curitiba / UNICURITIBA. Realizou estágio PósDoutoral na Universidade de Coimbra.

${ }^{2}$ Doutoranda em Direito Político e Econômico pela Universidade Presbiteriana Mackenzie - UPM. Mestre em Direito Empresarial e Cidadania pelo Centro Universitário Curitiba - UNICURITIBA. Especialista em Direito do Trabalho e Processual do Trabalho pela Pontifícia Universidade Católica do Paraná-PUCPR. Advogada e Professora Universitária.

${ }^{3}$ Doutoranda em Direito Político e Econômico pela Universidade Presbiteriana Mackenzie - UPM. MESTRADO em Direito Internacional E Econômico pela Universidade Católica De Brasília - UCB. Especialização em Direito Público E Em Direito Privado Pela Universidade Federal Do Piauí - UFPI. Advogada e Professora Universitária.
} 
As revoluções industrial e tecnológica trouxeram uma nova pauta de preocupação para a sociedade: qual o impacto terá a produção artificial contemporânea para as próximas gerações? Inicialmente, visualiza-se essa pauta no contexto do direito ambiental, pois, de fato, a vivência das futuras gerações está diretamente relacionada ao meio ambiente equilibrado. No entanto, todas as decisões políticas realizadas no seio da sociedade são passíveis de inserção nesse contexto apreensivo.

No âmago do direito, ao tratar desse assunto, fala-se em direito intergeracional, justiça intergeracional ou equidade intergeracional. Para fins didáticos, os termos serão utilizados como sinônimos que remetem à ideia de "justiça entre gerações". A essa luz, o direito intergeracional é o conjunto de normas que regula a responsabilidade jurídica das gerações viventes em relação às gerações futuras. Por gerações viventes, entende-se a geração de pessoas que vivem na mesma margem de fluxo temporal, já por gerações futuras, compreende-se as pessoas que viverão em uma mesma margem de fluxo temporal.

Modesto (2016) aponta que as indagações sobre a temática do direito intertemporal são recentes, daí a primeira justificativa para demonstrar a importância de se escrever um artigo sobre o tema: reforçar cada vez mais a preocupação com a responsabilidade intertemporal. Noutro sentido, descortina-se a relevância do artigo em razão da atualidade da temática tratada: a reforma da previdência social ante a crise do Estado Social. Nesse rumo, a temática é totalmente conectada com o direito intergeracional, tendo em vista que a previdência social brasileira é um pacto intergeracional, ou seja, as gerações atuais vertem contribuições para um fundo único para manter os benefícios da "velha geração"; posteriormente essa atual geração será mantida pela geração mais nova e assim sucessivamente.

Ainda, sobre a segunda justificativa para a produção deste trabalho, ressalta-se que o modelo de Estado Social atual, que prevê um modelo de previdência solidária, encontra-se em crise por diversos fatores que serão pontuados ao longo do texto, dentre eles, o aumento do desemprego. Por isso, se fala de forma enfática na necessidade de reforma do sistema de previdência social. Para além da justificativa da crise, argumenta-se a urgência da reforma em razão da chamada "crise de velhice”, ou seja, o aumento da população idosa causará um 
desequilíbrio no quantitativo de pessoas que contribuem e pessoas que usufruem dos benefícios. Mas, será que de fato, por argumentação focada na "crise da velhice", urge realizar a reforma da previdência social desde logo? Para responder a esse questionamento, fez-se uma análise do pacto intergeracional previdenciário sob a ótica do direito intergeracional. $\mathrm{O}$ exame desse pacto também foi analisado no âmago do tema "custos dos direitos".

O conteúdo do trabalho foi divido em 04 (quatro) tópicos, quais sejam, esta introdução; tópico 2: direito fundamental intergeracional; tópico 3: direito intergeracional e o custo dos direitos; subtópico 3.1. a previdência social brasileira; 3.2. a reforma da previdência e a elevação do custo dos direitos e; conclusão.

Para a confecção do artigo, adotou-se procedimento bibliográfico, utilizarem-se livros e artigos nacionais e internacionais sobre a temática "direito intergeracional" ou "justiça intergeracional", além disso, realizou-se pesquisa documental na legislação pertinente ao tema.

\section{DIREITO FUNDAMENTAL INTERGERACIONAL}

Comumente, os termos direito intergeracional, justiça intergeracional e equidade intergeracional remetem à ideia de proteção dos direitos das gerações vindouras. Nesse sentido, existem diversos trabalhos acadêmicos que abordam o tema da justiça entre gerações focando na questão ambiental, ou seja, na responsabilidade de preservação do meio ambiente pelas gerações contemporâneas em benefício das gerações futuras, bem como, no possível dissabor que as próximas gerações suportarão por conta da herança de resíduos produzidos por aqueles que vivem no presente. Basta um rápido exercício de pesquisa nos sites de busca da rede mundial de computadores com a inserção da expressão "justiça intergeracional" ou "direito intergeracional" para constatar essa afirmação.

Nesse diapasão, o tema da justiça intergeracional circunda consideravelmente nas entranhas do direito ambiental, por conta da previsão contida no artigo 225 da Constituição Federal de 1988, que impõe ao Poder Público e à coletividade o dever de defender e preservar o meio ambiente para as presentes e futuras gerações. Trata-se do denominado princípio da solidariedade intergeracional.

Todavia, a temática em questão não é exclusivamente voltada para a problemática ambiental. Desse modo, os vocábulos em evidência também são utilizados para fazer referência a um conjunto de preocupações éticas e jurídicas da contemporaneidade (MODESTO, 2016) como por exemplo, as escolhas na condução da política econômica de um país. Assim sendo, à título de contextualização, no âmago de uma reforma previdenciária de abrangência nacional, 
as adversidades, porventura enfrentadas pelas próximas gerações, decorridas da implementação de um sistema de capitalização pela geração atual são objetos de estudo da justiça intergeracional? A resposta é afirmativa.

Partindo desse contexto e o aprofundando de maneira reflexiva, é possível pensar em contratempos de caráter jurídico passíveis de verticalização, inerentes às nuances gerais do tema da justiça intergeracional. Reflete-se, inicialmente, da seguinte forma: a menção às gerações futuras que suportarão as possíveis tribulações provocadas pelas gerações atuais está sacramentada em sentido cronológico-temporal ou cronológico-intertemporal? Invoca-se esse raciocínio na medida em que Tremmel (apud Modesto, 2016) distingue a geração em sentido cronológico-temporal da geração em sentido cronológico-intertemporal. Em sentido cronológico-temporal, a expressão "geração" alude a um grupo de indivíduos da mesma idade no bojo de uma sociedade. Fala-se então em "nova geração" - pessoas que estão abaixo dos 30 (trinta) anos -, "geração de meia-idade" - pessoas entre 30 (trinta) e 60 (sessenta) anos - e "velha geração" - aqueles com mais de 60 (sessenta) anos. Por outro lado, em sentido cronológico-intertemporal, a palavra "geração" reporta-se aos indivíduos que vivem no presente, aos que viveram no passado e os que viverão no futuro - portanto, tem-se, respectivamente, a ideia de "geração vivente", "geração passada" e "geração futura".

Estabelecida essa distinção, é possível agora expor outra reflexão: se a possibilidade de manter a sociedade em níveis otimizados de desenvolvimento por um longo período de tempo está diretamente ligada às ações que gravitam em torno da responsabilidade das "gerações viventes" perante as "gerações futuras", então o cumprimento de ações responsáveis na contemporaneidade, que podem ser pontuadas em um pacto intergeracional promovido pelas gerações atuais, é direito das gerações posteriores? Ademais, se de fato for um direito, trata-se de um direito sem sujeitos? Fala-se em "direito sem sujeitos" porquanto a relação intergeracional demonstrada nessa segunda consideração é estabelecida em consonância com o significado de "geração" em sentido cronológico-intertemporal, assim sendo, quando se fala em "direito da geração futura", está implícita a ideia de direito atribuído a uma geração que ainda não existe - de um direito sem sujeitos.

Sequeira (2017), apesar de pormenorizar o assunto na conjuntura do direito português, traz contributos importantes para o entendimento da atribuição de direitos às gerações vindouras. A essa luz, a autora coloca em xeque a recusa em qualificar como ilícitos os fatos que violam direitos das gerações futuras. Rejeita-se essa qualificação com esteio na ideia de que inexiste transgressão passiva - e ilicitude - na situação de "violação a direitos das gerações futuras", pois não há direito. Como sintetiza Sequeira (2017, p. 19-20), "por não haver sujeito, 
não há direito; por não haver direito, não há ilicitude. Ou, de outro prisma, por não haver sujeito, não há direito; por não haver direito, não há dever genérico de respeito; por não haver dever genérico de respeito, não há ilicitude".

A princípio, a argumentação da ausência de tutela do direito em face das relações intergeracionais soa injusta. Isso porque a não incidência da atributividade - característica que, segundo Reale (2002), distingue essencialmente o direito de outras formas de controle social retira a exigibilidade jurídica, dotada de força cogente, da relação formada entre as gerações viventes e as gerações futuras. A consequência disso é o estabelecimento da responsabilidade das gerações presentes em face das gerações posteriores como facultatividade, não como obrigação. Esse efeito também leva à eventual condução desajustada da sociedade, visto que desperta espaços para condutas abusivas das gerações atuais, como por exemplo, a contratação desenfreada de empréstimos a juros flutuantes, fato que culminará em um legado de dívida pública galopante para as gerações do futuro. Percebe-se, com isso, que a exclusão das relações intergeracionais do círculo do direito denota o enfraquecimento de um dos próprios objetivos centrais do direito, qual seja, o progresso da sociedade.

Sequeira (2017) reconhece a fragilidade em enquadrar os direitos das gerações futuras como direitos sem sujeitos. A autora até demonstra situações jurídicas no direito português cuja transitoriedade da inexistência de sujeitos é admitida - é o caso da herança jacente -, porém, haveria empecilho em alocar os direitos intergeracionais nessa categoria, por conta do objeto a ser tutelado. Portanto, ante uma análise estrutural da relação jurídica entre as gerações viventes e as gerações futuras, detectou-se obstáculo no elemento objetivo, e não subjetivo, já que a figura dos direitos sem sujeitos é juridicamente admissível, ainda assim, a nível temporal, não há que se falar em direitos subjetivos das gerações vindouras no presente. Frisa-se que a controvérsia do elemento objetivo reside no seu caráter futuro.

Entrementes, a questão ainda não é encerrada, ou seja, não é sacramentado que não há direitos em prol das gerações futuras. Em verdade, o exame da relação jurídica em destaque é merecedor de outra perspectiva, diferente da que procura vincular o resguardo dos direitos das gerações posteriores às próprias gerações vindouras. Sequeira $(2017$, p. 36) corrobora essa visão ao afirmar que o "direito da geração vindoura é futuro, mas a vinculação da geração atual é presente".

Explica-se a existência dessa vinculação através da presença das normas fundamentais de conteúdo intertemporal. Tais normas contém valores que tutelam os direitos futuros, impondo à geração atual o dever de não praticar quaisquer atos que comprometam o avanço ou concretização desses direitos. Como observa Sequeira (2017, p. 37), “da simples vigência da 
norma decorre, portanto, a proibição de inviabilizar o nascimento dos direitos fundamentais da geração vindoura ou de os esvaziar por completo".

A partir desse raciocínio, emana a seguinte indagação: a constante necessidade de observância de viabilidade do bem-estar da coletividade do futuro, imposta por norma fundamental, é capaz de criar empecilhos que provoquem insuportáveis tumultos sociais na geração contemporânea? Além disso, caso haja essa capacidade, as normas fundamentais sobre direitos intergeracionais passariam a ser consideradas ineficazes ou inefetivas? Em primeiro lugar, é imperioso pontuar que a observância da norma não se confunde com a sua eficácia ou efetividade, assim, uma norma pode ser eficaz ou efetiva, mesmo sem a obediência integralmente do preceito contido nela. Nesse sentido, Ferraz Jr. (2003, p.193-194) leciona que "existem exemplos de normas que nunca chegam a ser obedecidas e, não obstante isso, podem ser consideradas socialmente eficazes". Trata-se de normas reclamadas ideologicamente pela sociedade, que não chegam a ser integralmente obedecidas - sob pena de causarem verdadeiro tumulto social -, porém, são parcialmente observadas para produzirem efeito de agrado ideológico (FERRAZ JR., 2003).

Não obstante, o conteúdo das normas intergeracionais - como é o caso da solidariedade intergeracional do meio ambiente - também produzem impactos na geração vivente. Dessa maneira têm-se os efeitos concretos imediatistas provindos da aplicação das normas em comento. Com isso, o manejo dos preceitos normativos de conteúdo intergeracional exige ponderação, demandando, portanto, razoabilidade e proporcionalidade em sua aplicabilidade enquanto normas fundamentais -, ou seja, é crucial a mensuração dos efeitos do emprego prático das normas de teor intergeracional. Fica nítida aqui a relação de intercâmbio entre as gerações presentes e as gerações futuras: se as gerações atuais criarem um cenário de escassez recursal, as gerações futuras tendem ao perecimento - quebra-se, desse modo, o pacto intergeracional.

Denota-se a partir desse contexto, que o direito intergeracional inquire a transversalidade jurídica para além do próprio direito, pois a análise de impactos do manejo prático do direito entre as gerações acarreta o diálogo com os mais variados campos do conhecimento. Por exemplo, a aplicação das políticas intergeracionais pelo Estado se dá por meio de políticas públicas, então, quando há abordagem dinâmica dessa temática, invoca-se o conhecimento da ciência política, da gestão pública, da administração etc.

Inclusive, cabe salientar que existem dificuldades na aplicação prática dos direitos intergeracionais. A primeira dificuldade é de cunho político. Nesse rumo, observa-se que é perceptível o caráter não imediatista das políticas intergeracionais. A título exemplificativo, se 
o governo reforça positivamente os dispositivos que tutelam o meio ambiente para fins de diminuição do impacto dos poluentes nas grandes cidades, os resultados advindos dessa reforma serão constatados a longo prazo.

Entretanto, de modo secundário, a mudança na legislação ambiental poderá surtir impressões negativas em setores econômicos que exploram diretamente o ambiente natural. Tais setores, muitas vezes por serem alavancadores dos superávits econômicos, acabam tornando-se influenciadores diretos das decisões governamentais, sendo assim, ante esse jogo de interesses, surgem obstáculos para o avanço de "políticas de interesses opostos". Na realidade, como a eficiência das decisões políticas marca a probabilidade de eleição ou reeleição do candidato ao poder, a tendência é que as escolhas da gestão sejam marcadas por políticas de efeito positivo imediato - fato que lateraliza as políticas de cunho intergeracional.

Esse cenário problemático é visualizado por Silva (2017) ao analisar um brocardo crítico sobre a política atual: “em política não há gerações futuras, só as eleições seguintes”. Para o autor, isso representa "a forma atual de fazer política de curto prazo, com os olhos postos apenas na obtenção de proventos eleitorais imediatos" (SILVA, 2017, p. 93-94).

A segunda dificuldade prática de aplicação dos direitos intergeracionais decorre da lógica da responsabilidade decrescente provinda do afastamento das gerações em sentido cronológico-temporal, em outras palavras, da não aproximação entre a "nova geração" e a "velha geração". Nigri (2002) aponta para a tendência da "nova geração" seguir um fluxo de aproximação dos laços interpessoais entre os seus semelhantes - isolando, portanto, os membros da "velha geração". Assim, a conscientização do direito fundamental ao pacto intergeracional é prejudicada pela crise de identidade entre as gerações sociais.

Identificam-se também dificuldades teóricas para a aplicação dos direitos intergeracionais. Tal repulsão decorre da ausência do caráter de idealismo desses direitos, talvez por serem dotados de um núcleo estrutural composto por um quantitativo considerável de deveres, que se materializam por racionamento de direitos contemporâneos. Explicando melhor essa problemática: percebe-se que na grande maioria das faculdades de Direito há um ciclo de ensino que aloca a sociedade como espaço incondicional para a conquista de direitos - tem-se, então, um ensino jurídico idealista. Esse ensino forma juristas desatentos para a aplicação condicional dos direitos - especialmente os direitos sociais. Tal aplicação é condicionada especialmente por fatores quantitativos, como os custos de operacionalização.

Decorre daí o empobrecimento teórico dos direitos intergeracionais: como teorizar um direito que necessita de análise econômica, se ao longo da formação acadêmica os juristas são tolhidos do ensino acerca dos custos dos direitos? Uma boa forma de solucionar parte do 
problema seria por meio da inserção da cadeira de análise econômica do direito nos cursos de graduação de Direito.

\section{DIREITO INTERGERACIONAL E O CUSTO DOS DIREITOS}

Partindo do pressuposto do idealismo jurídico na aplicação dos direitos, é possível dizer que alguns temas dos direitos intergeracionais são mais aceitos do que outros. Por exemplo, defender a preservação do meio ambiente em prol das gerações futuras é mais aceitável do que advogar por uma ampla reforma na previdência social. Nessa visão, consideram-se apenas a questão da ampliação ou redução de direitos, sem considerar, contudo, os custos desses atos.

Quando se fala nessa prática de consideração dos custos do direito, muitos pensam logo na questão da denominada "reserva do possível", que parte da premissa de que a escassez dos recursos estatais exige a preterição de algumas demandas sociais em detrimento de outras. Porém, a análise de custos não envolve só a questão da preterição, mas também a questão do aumento da riqueza social tributável. Explica-se: as demandas sociais são custeadas em grande parte por tributos, que são receitas provindas da própria sociedade, portanto, aumentar o número de contribuintes dos tributos é essencial para que as demandas da sociedade sejam atendidas com eficiência, esse aumento da riqueza tributável muitas vezes está ligada com a concessão de alguns direitos para membros da sociedade que se tornam aptos a contribuírem com a receita tributária.

Sobre o tema "custos dos direitos", Holmes e Sustein (2005) indicam que os custos podem ser não monetários, como os denominados custos sociais, cujo exemplo citado pelos autores são os custos despendidos para a proteção dos direitos do acusado criminal. Ademais, os autores apontam que os custos também podem ser monetários ou orçamentários, nessa espécie, o cumprimento e proteção de direitos dependem das verbas disponibilizadas no erário. Em verdade, o cumprimento dos direitos abrangidos pelos custos sociais deve observância à disponibilidade dos custos orçamentários. Atenta-se, então, para o fato de que quaisquer espécies de direitos possuem custos para o tesouro. Até mesmo os denominados direitos autofinanciáveis, que são aqueles que majoram a riqueza social tributária de forma razoável são capazes de impactar o orçamento a longo prazo.

Homes e Sustein (2005) alertam que a manutenção do oferecimento de direitos fundamentais pelo Estado é contingente à alocação do problema da escassez de recursos no centro da logística de preservação de direitos da sociedade, dessa maneira, é imperioso pensar na política de custos de direito como algo altruísta. No entanto, os autores apontam para o fato 
de que há um tabu sobre a discussão dos custos dos direitos, porquanto a pauta dessa discussão aparenta ser uma ameaça à preservação dos direitos. Desse ponto, percebe-se as semelhanças entre os obstáculos enfrentados pelos direitos intergeracionais e pela inclusão do problema da escassez nos direitos - assim como, a consideração dos custos dos direitos: ambos enfrentam problemas nas escolhas políticas e na teorização pelos juristas. Do ponto de vista político, é impopular mitigar direitos visando a preservação de custos, dessa forma, há preferência, nas decisões políticas, em realizar verdadeiros malabarismos orçamentários para manter a concessão de direitos à sociedade - mais uma vez, prevalecendo decisões imediatistas, porventura, inconsequentes.

Quando há junção das duas temáticas - direitos intergeracionais e aplicação da política de custos nos direitos - tem-se a ampliação dos problemas que giram em seus entornos. Contudo, surge também a possiblidade de refletir sobre até que ponto a escassez dos recursos financeiros deve ser considerada para a aplicação dos direitos intergeracionais. Sobre essa reflexão, volta-se a questão de que alguns temas que envolvem direitos intergeracionais são mais aceitos do que outros. Por exemplo, quando se pensa na questão da preservação do meio ambiente, é mais aceitável para a população que parte significativa do orçamento seja destina à prevenção de danos contra a natureza, pois preservar a natureza implica na melhoria da qualidade de vida das pessoas, do contrário, quando se anuncia cortes orçamentários para esse setor, há um número maior de críticas emanadas pelos cidadãos, o mesmo efeito é visto quando se discute a reforma da previdência, porquanto a modificação nas regras do sistema previdenciário implicam em onerações para os trabalhadores, como a redução do valor de benefícios previdenciários e o aumento na idade para pleitear a aposentadoria.

\section{SOLIDARIEDADE DA PREVIDÊNCIA SOCIAL, CRISE SOCIAL E A MANUTENÇÃO DO PACTO INTERGERACIONAL}

\subsection{A previdência social brasileira}

A previdência social brasileira está inserida no sistema de seguridade social juntamente com a saúde e a assistência social. Apesar da presença de um sistema jurídico previdenciário no Brasil desde 1923, com a publicação da Lei Eloy Chaves, a estruturação do sistema de seguridade brasileiro ocorreu somente com a promulgação da Constituição de 1988.

No âmago desse sistema, aloca-se a saúde e a assistência social ao subsistema não contributivo, pela ausência da necessidade de contrapartida financeira para usufruir dos benefícios e serviços daquelas áreas. Por outro lado, o subsistema contributivo engloba a 
previdência social. Assim, para fazer jus aos benefícios e serviços previdenciários, é preciso verter contribuições em favor dos cofres da previdência. Para Amado (2018, p. 251), "trata-se de um sistema contributivo de repartição e não de capitalização, pois restou instituído fundo único para o pagamento dos benefícios previdenciários, sendo possível que determinados benefícios sejam concedidos mesmo que ainda não haja uma contribuição sequer ao sistema".

Portanto, a previdência é um verdadeiro sistema de seguro para o trabalhador e seus dependentes, que os protege de riscos como a doença, a velhice, a incapacidade para o labor etc. Os sistemas de previdência, de acordo com o ato de filiação, podem ser classificados em obrigatórios ou facultativos. Dentre os sistemas obrigatórios encontram-se o Regime Geral de Previdência Social, sob encargo da União, e os Regimes Próprios de Previdência, instituídos em prol dos servidores civis da União, Estados e Municípios.

O ato de filiação ao RGPS proporciona ao cidadão segurado, depois de atendidas as condições estabelecidas em lei, o gozo de benefícios e serviços da previdência social.

Segundo a Lei n ${ }^{\circ} 8.213 / 1991$, que trata dos planos de benefícios do RGPS, existem 08 (oito) benefícios disponíveis ao segurado: aposentadoria por invalidez, aposentadoria por idade, aposentadoria por tempo de contribuição, aposentadoria especial, auxílio-doença, saláriofamília, salário-maternidade e auxílio-acidente; 02 (dois) benefícios disponíveis aos seus dependentes: pensão por morte e auxílio-reclusão; e 02 (dois) serviços ofertados aos segurados e dependentes: serviço social e reabilitação profissional.

A manutenção desse sistema é proporcionada por uma multiplicidade na fonte de custeio. Desse modo, conforme o artigo 195 da Constituição de 88, a seguridade social brasileira é custeada por: contribuições das empresas, dos empregadores e equiparados, que incidem sobre a folha de salários e demais rendimentos do trabalho pagos ou creditados a qualquer título à pessoa física que preste serviço, mesmo sem vínculo empregatício - trata-se da contribuição patronal previdenciária - incidem ainda sobre a receita ou faturamento COFINS - bem como sobre o lucro - CSLL; contribuições de trabalhadores e demais segurados do RGPS; concursos de prognósticos; contribuição do importador de bens ou serviços do exterior - COFINS IMPORTAÇÃO.

As contribuições dos trabalhadores e demais segurados do RGPS e as contribuições patronais são receitas de arrecadação afetadas ao pagamento dos benefícios e prestação de serviços do RGPS, conforme o artigo 167, inciso XI, da Constituição.

Assim, dentro da perspectiva orçamentária, as receitas previdenciárias são inflexíveis, pois enquanto afetadas, não poderiam, em regra, ter destinação diversa do cofre da previdência social. Porém, o governo federal, por meio de mecanismo, previsto no artigo 76 do Ato das 
Disposições Constitucionais Transitórias (ADCT), denominado DRU (Desvinculação das Receita da União), torna o orçamento mais flexível.

A sistemática da previdência também é justificada em razão de um dos princípios que norteiam a seguridade social no Brasil, qual seja, a solidariedade. Sobre o respectivo princípio, Zélia Pierdoná (2015, p. 98) afirma que a "solidariedade sempre foi o fundamento da proteção social, efetivando-se em grupos menores, como a família, até grupos maiores, como a sociedade organizada, por meio do Estado". O fundamento legal da solidariedade encontra-se no artigo $3^{\circ}$, inciso I, da Constituição, enquanto objetivo a ser atingido pelo Estado brasileiro. Ademais, os artigos 194 e 195 da Constituição também consagram a solidariedade ao disciplinarem, respectivamente, as ações e o financiamento da seguridade social como responsabilidade de toda a sociedade. Assim, conforme pontua Pierdoná (2015, p. 98), “o princípio da solidariedade desempenha papel fundamental na seguridade social, a qual, por ter um caráter universal, proporciona proteção a todos aqueles que estão em situação de necessidade".

Entrementes, esse modelo de solidariedade, provindo das ideologias do Estado do BemEstar Social, encontra-se em crise: a denominada crise do Estado Social.

\footnotetext{
Não constitui novidade que os fatores mais incontornáveis dessa crise são essencialmente três: a redução consistente das taxas de crescimento econômico, que, com alguma oscilações conjunturais, nunca mais atingiram os níveis anteriores às crises petrolíferas; a inversão progressiva da pirâmide demográfica, com a redução paulatina das taxas de natalidade e com o alargamento notável de esperança média de vida e, consequentemente, com a diminuição do ratio de trabalhadores ativos por dependente; o aumento estrutural dos níveis de desemprego, que provoca simultaneamente redução das contribuições e aumento das prestações devidas (SILVA, 2017, p. 101).
}

O fluxo contínuo dessa crise traz um desgaste social que tem como consequência o requerimento efusivo por reformas que revertam a estagnação econômica, é a partir daí que ocorre o reforço do pacto intergeracional, ainda que esse reforço seja emanado como efeito mediato. Isso também motiva a sociedade a pensar nos custos dos direitos e na adequação do modelo atual de previdência social.

\subsection{A reforma da previdência e a elevação do custo dos direitos}

Desde os anos 90, já se falava sobre a denominada "crise da velhice" mundial. Simões (1997) informa que essa "crise" foi alertada pelo Banco Mundial com ênfase em dois fatores: o aumento da expectativa de vida e o declínio da fecundidade. 
Um dos objetivos ou princípios da previdência social é o equilíbrio financeiro e atuarial do sistema, previsto no artigo 201 da Constituição, que tem por finalidade "assegurar a incolumidade das contas previdenciárias para as presentes e futuras gerações” (BRASIL, 1988). Não se trata, assim, de objetivo que leve em consideração - estritamente - a saúde financeira atual do sistema previdenciário, mas sim, que vislumbra uma tendência passível de afetar as contas da previdência social no futuro. Dessa maneira, o principal fator atual de desequilíbrio financeiro e atuarial, bem como, principal argumento para a reforma pela perspectiva intergeracional, é a mutação demográfica eminente, conforme veem demonstrando as pesquisas do $\mathrm{IBGE}^{4}$.

Os sinais de desequilíbrio na previdência também são vislumbrados em razão do acréscimo de faixa etária mínima para a concessão das aposentadorias por tempo de contribuição e pelo crescimento da expectativa de vida da população brasileira ${ }^{5}$.

Outro fator que impulsiona o desequilíbrio previdenciário é o déficit arrecadatório quando há a soma da parte urbana com a parte rural, o que é plausível, pelo fato das regras de concessão de benefícios e serviços em prol de grande parte dos trabalhadores rurais - os segurados especiais - exigirem contraprestações diferenciadas, menos onerosas que as exigidas em face dos trabalhadores urbanos ${ }^{6}$.

Em temos quantitativos, segundo o Fluxo de Caixa do INSS, em 2015 a previdência rural atingiu o saldo negativo de aproximadamente $\mathrm{R} \$ 91$ bilhões, enquanto a previdência urbana possui saldo positivo de aproximadamente $\mathrm{R} \$ 5,1$ bilhões.

Em 2018, segundo dados do Tesouro Nacional, os benefícios previdenciários concedidos totalizaram 589,51 bilhões de reais, enquanto a receita das contribuições previdenciárias totalizou 395 bilhões de reais. A tendência é que as receitas não consigam suprir as despesas com a previdência nos próximos anos, em razão da estagnação econômica brasileira. Com isso, Pierdoná alerta que a situação deficitária da previdência atrelada aos desafios da longevidade populacional agrava - ainda mais - a situação de equilíbrio financeiro e atuarial da previdência social.

\footnotetext{
${ }^{4}$ Disponível em:<http://www.camara.gov.br/proposicoesWeb/prop_mostrarintegra;jsessionid=E5FF44C8E5ABC2ED3FC80 5FF830EB6D9.proposicoesWebExterno2? codteor $=1514975 \&$ filename $=\mathrm{PEC}+287 / 2016>$

${ }^{5}$ Disponível em:

<http://www.camara.gov.br/proposicoesWeb/prop_mostrarintegra;jsessionid=E5FF44C8E5ABC2ED3FC805FF 830EB6D9.proposicoesWebExterno2?codteor $=1514975 \&$ filename $=\mathrm{PEC}+287 / 2016>$
}

\footnotetext{
${ }^{6}$ Tal fato é constatado através da comparação entre as regras de concessão de benefícios e de serviços dos trabalhadores urbanos e dos trabalhadores rurais no RGPS, previstas na Lei no 8.213/1991.
} 


\section{CONCLUSÃO}

O direito intergeracional necessita de maior estruturação doutrinária, especialmente por parte dos juristas brasileiros, que ficam especialmente atrelados à questão da solidariedade intergeracional ambiental. Assim, é preciso expandir a temática para outras áreas que também demandam a aplicação desse direito, como o direito previdenciário.

Através da pesquisa na doutrina portuguesa, constatou-se que o direito intergeracional é um direito fundamental das futuras gerações. Todavia, trata-se de um direito fundamental de aplicação prática dificultosa, essencialmente por duas razões: a) a razão política, que decorre do caráter não imediatista dos resultados práticos das políticas públicas intergeracionais, fato que, por razões eleitoreiras, desestimula os governantes a adotá-las; b) a razão psicossocial, decorrente da responsabilidade decrescente provinda do afastamento das gerações em sentido cronológico-temporal, em outras palavras, da não aproximação substancial entre a "nova geração" e a "velha geração".

Inserindo a temática no contexto da previdência, conclui-se que a reforma deve circundar em torno de um debate técnico-democrático, sem qualquer espaço ao apelo emotivo de interesses políticos imediatistas. Pelo que foi apresentado no trabalho, as constantes crises fiscais não garantem a manutenção do equilíbrio arrecadatório desse tributo, porquanto as receitas das contribuições previdenciárias não acompanham a evolução das despesas com benefícios do RGPS.

Acerca dos gastos com a previdência brasileira, se faz relevante observar a concessão de direitos a luz dos seus custos, ou seja, dos custos dos direitos. É necessário que os juristas passem a ter em mente que os recursos estatais são escassos, bem como, que a própria manutenção - presente e futura - dos direitos fundamentais, como é o caso do sistema previdenciário, depende da racionalização dos recursos provindos dos orçamentos públicos.

Ademais, não se pode fechar os olhos para o aumento vertiginoso da expectativa de vida dos brasileiros e o aumento da população idosa - "crise da velhice". Não se trato a de penalizar o estado senil da população, mas sim de equilibrar o sistema de seguridade social para todas as gerações.

O equilíbrio financeiro e atuarial da previdência depende do enfretamento conjunto dessas duas adversidades: envelhecimento populacional e crise fiscal do Estado. Tudo em prol da manutenção do pacto entre gerações que circunda o sistema previdenciário brasileiro. 
Assim, o cumprimento do direito fundamental ao pacto intergeracional deve ser realizado em um debate tecnicista que equilibre os interesses das gerações futuras, sem sucumbir os planos progressivos da atual geração.

\section{REFERÊNCIAS}

AMADO, Frederico. Direito previdenciário. $6^{\mathrm{a}}$ ed. Salvador: Juspodivm, 2015.

AMADO, Frederico. Curso de direito e processo previdenciário. 10. ed. rev. ampl. e atual. Salvador. Juspodivm, 2018.

BRASIL. Constituição da República Federativa do Brasil (1988). Promulgada em 05 de outubro de 1988. Disponível em: www.planalto.gov.br/ccivil_03/constituicao/constituicao.html> Acesso em 05 mai. 2019.

BRASIL. Ministério do planejamento, orçamento e gestão. Evolução recente da carga tributária federal.

Em:

<http://www.planejamento.gov.br/secretarias/upload/arquivo/assec/evolucao-recente-dacarga-tributaria-federal-3.pdf > Acesso em 06 mai. 2019.

BRASIL. Proposta de emenda constitucional no 287 de 2016. Altera os arts. 37, 40, 109, 149, 167, 195, 201 e 203 da Constituição, para dispor sobre a seguridade social, estabelece regras de transição e dá outras providências. <http://www.camara.gov.br/proposicoesWeb/prop_mostrarintegra;jsessionid=E5FF44C8E5A BC2ED3FC805FF830EB6D9.proposicoesWebExterno2? codteor $=1514975 \&$ filename $=$ PEC + 287/2016> Acesso em 06 mai. 2019.

IBRAHIM, Fábio Zambitte. Governo Federal inicial mais uma reforma previdenciária por MP. Em: <http://www.conjur.com.br/2015-jan-07/fabio-zambitte-reforma-previdenciariainicia> Acesso em 06 mai. 2019.

PIEDORNÁ, Zélia Luiza. O sistema de seguridade social brasileiro. In: Marco Antônio César Villatore; Francisca Moreno Romero (org.). III Encontro de Internacionalização do CONPEDI/Madrid/Espanha. 1. ed. Madrid: Ediciones Laborum, 2015, v. 6, pp. 87-104.

PISCITELLI, Roberto Bocaccio. O teto de gastos. In: Jornal dos economistas. Rio de Janeiro, 2016.

REALE, Miguel. Lições preliminares de direito. 27. ed. São Paulo: Saraiva, 2002. 
SEQUERA, Elisa Vaz de. Direitos sem sujeitos?. In: Justiça entre gerações - perspetivas interdisciplinares. SILVA, Jorge Pereira e RIBEIRO, Gonçalo de Almeida (coords.) Universidade Católica: Lisboa, 2017.

SILVA, Jorge Pereira da. Justiça intergeracional: entre a política e o direito constitucional. In: Justiça entre gerações - perspetivas interdisciplinares. SILVA, Jorge Pereira e RIBEIRO, Gonçalo de Almeida (coords.) Universidade Católica: Lisboa, 2017.

SIMÕES, Júlio Assis. Solidariedade intergeracional e reforma da previdência. Dossiê Gênero e Velhice, p. 169-181, 1997.

MODESTO, Paulo. Uma introdução à teoria da justiça intergeracional e o direito. Disponível em: http://www.direitodoestado.com.br/colunistas/paulo-modesto/uma-introducaoa-teoria-da-justica-intergeracional-e-o-direito. Acesso em 01 de mai. de 2019.

NERY, Pedro Fernando. Reforma da previdência: uma introdução em perguntas e respostas. Disponível em em: <http://www12.senado.leg.br/publicacoes/estudoslegislativos/tipos-de-estudos/textos-para-discussao/td219> Acesso em 05 de mai. 2019.

NIGRI, Sara. O conceito de gerações e as relações intergeracionais. Disponível em: http://prattein.com.br/home/index.php?option=com_content \&view=article\&id=736:0conceito-de-geracoes-e-as-relacoes-intergeracionais\&catid=98:estudos-e-indicadores-sobreenvelhecimento\&Itemid=188. Acesso em 07 de mai. 2019.

TAVARES, Marcelo Leonardo; MANNARINO, Anna Clements. Igualdade de gênero e reforma da previdência. Revista Jurídica, [S.1.], v. 3, n. 48, p. 147 - 168, set. 2017. ISSN 2316$753 X$. Disponível

em: <http://revista.unicuritiba.edu.br/index.php/RevJur/article/view/2219/1393>. Acesso em: 23 abr. 2020. doi:http://dx.doi.org/10.21902/revistajur.2316-753X.v3i48.2219. 